\title{
Fragmentation Properties of Metals
}

D. E. Grady and M. E. Kipp

Sandia National Laboratories

Albuquerque, New Mexico, USA 87185
RECEVED

Jü 041996

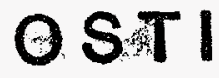

\section{ABSTRACT}

In the present study we are developing an experimental fracture material property test method specific to dynamic fragmentation. Spherical test samples of the metals of interest are subjected to controlled impulsive stress loads by acceleration to high velocities with a light-gas launcher facility and subsequent normal impact on thin plates. Motion, deformation and fragmentation of the test samples are diagnosed with multiple flash radiography methods. The impact plate materials are selected to be transparent to the $\mathrm{x}$-ray method so that only test metal material is imaged. Through a systematic series of such tests, both strain-to-failure and fragmentation resistance properties are determined through this experimental method. Fragmentation property data for several steels, copper, aluminum, tantalum and titanium have been obtained to date. Aspects of the dynamic data have been analyzed with computational methods to achieve a better understanding of the processes leading to failure and fragmentation, and to test an existing computational fragmentation model.

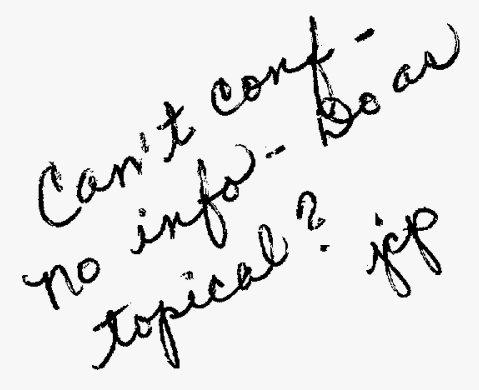

This work was supnoried by the United

\section{MASTER}




\section{DISCLAIMER}

This report was prepared as an account of work sponsored by an agency of the United States Government. Neither the United States Government nor any agency thereof, nor any of their employees, make any warranty, express or implied, or assumes any legal liabifity or responsibility for the accuracy, completeness, or usefuiness of any information, apparatus, product, or process disclosed, or represents that its use would not infringe privately owned rights. Reference herein to any specific commercial product, process, or service by trade name, trademark, manufacturer, or otherwise does not necessarily constitute or imply its endorsement, recommendation, or favoring by the United States Government or any agency thereof. The views and opinions of authors expressed herein do not necessarily state or reflect those of the United States Government or any agency thereof. 


\section{DISCLAMMER}

Portions of this document may be illegible in electronic image products. Images are produced from the best available original document. 


\section{INTRODUCTION}

Some basic theories have emerged within the past 10 years for predicting the consequences of dynamic fragmentation brought about by high-velocity impact or explosive events. These theories have focused principally on the prediction of mean fragment size through energy and momentum balance principals (e.g. Grady, 1982; Kipp and Grady, 1985; Glenn and Chudnovsky, 1986; Grady, 1988), and on the statistical issues of fragment size distributions (e.g. Englman, et al., 1984; Grady and Kipp, 1985; Brown, 1989; Grady, 1990). These theoretical bases are providing the underlying framework for a number of computational algorithms employed to analyze complex fragmentation events (e.g. Smith, 1989; Johnson, et al., 1990; Melosh, et al., 1992; Kipp, et al., 1993).

There are, nonetheless, a number of unresolved issues within the development of statistical energy-balance theories of fragmentation, and there is a pressing need for high-resolution experimental data focused on the validation of these theories. Furthermore, implementation and validation of these theories in numerical wave propagation codes is needed so that extensions can be made to the investigation of dynamic fragmentation in complex large scale catastrophic events.

A critical issue is a need for failure and fragmentation material property data which characterize material behavior under intense stress-wave loading for solids of interest. Although static fracture data frequently exist for these materials, the current state of theoretical understanding does not provide for the confident extension of these static data into the highly dynamic regime.

In the present study, we are exploring the possibilities of using a newly developed impact fracture and fragmentation experimental method to determine dynamic failure and fragmentation properties of metals. A sample of the test material is prepared in the form of a solid sphere and launched with a light-gas gun facility. The test sphere is caused to impact a thin plate of lowdensity non-metallic material and to undergo catastrophic fragmentation. Flash radiography is used to image the fragmented specimen at several stations. Only the metal debris is imaged on the 
radiograph because of the low density of the impact plate material. From the extent of fragmentation and the velocity of debris expansion, fragmentation properties of the metal are inferred. These properties include measures of the strain or deformation to failure, the energy absorbed before onset of fragmentation and the resistance or toughness of the material to fragmentation. In subsequent sections, exploratory studies and the development of this work is described. Numerical analysis is used to complement and to support interpretation of the experiments. These numerical analyses also enable an existing computational fragmentation theory to be evaluated including, the material parameters that are used in this theory.

\section{EXPERIMENTAL METHODS AND CONFIGURATION}

In the present material property test method, a sample of the metal of interest is prepared as a solid sphere. By methods to be described, the sample is subjected to a controlled impulsive load. Plastic deformation, failure and the intensity of fragmentation are features of the responses monitored within a test series.

Under modest impulsive loads, the spherical sample is deformed, but failure and subsequent fragmentation do not occur. By observing deformation over several tests up to the failure state, a measure of the strain-to-failure for the material of interest is achieved. For impulsive loads which exceed the breakup threshold of the test sample, fragmentation and expansion of the resulting debris occur. Fragment debris expansion characteristics are exploited to establish input energy levels needed to achieve failure and breakup. Statistical size characteristics are used to determine dynamic fracture resistance properties of the material.

\section{Experimental Configuration and Parameters}

The experimental configuration used to investigate the fragmentation properties of metals is shown in Figure 1. Solid metal spheres mounted in lexan sabots were launched at velocities from about 3 to $5 \mathrm{~km} / \mathrm{s}$ with a two-stage light-gas gun system. The diameter of the launch tube used was 
$12 \mathrm{~mm}$. Plastic sabots were separated from the metal spheres through forces produced by a rarefied atmosphere in the gun range section. Sabot segments were trapped upstream and did not reach the target impact chamber. Velocity of the metal spheres was measured to $\pm 1 \%$ accuracy by recording of the time interval during passage between two magnetic coils of known separation. Normal impact occurred in the target chamber at the center of a thin stationary plate. In a number of the tests, this plate was a $75 \mathrm{~mm}$ by $75 \mathrm{~mm}$ square of PMMA (polymethyl-methacrylate) Rohm and Haas Type II UVA (density $1186 \mathrm{~kg} / \mathrm{m}^{3}$ ). In tests where more intense impulsive loads were required, similar thickness glass (GE dynasil 1000, density $2201 \mathrm{~kg} / \mathrm{m}^{3}$ ) or aluminum oxide (GE lucolax, density $3969 \mathrm{~kg} / \mathrm{m}^{3}$ ) were used as barrier materials. In all tests, metal spheres approximately $6.35 \mathrm{~mm}$ (1/4 inch) in diameter were used as the test samples.

\section{Radiographic Techniques}

Deformed sample spheres or fragment debris were diagnosed at two stations (approximately $150 \mathrm{~mm}$ and $300 \mathrm{~mm}$ ) downstream from the impact point. Two $150 \mathrm{keV}$ flash $\mathrm{x}$-ray tubes, placed approximately $400 \mathrm{~mm}$ from the line of debris travel, provided orthogonal shadow-graphs of the fragment debris, as shown schematically in Figure 1. Appropriate delay times were calculated from the predicted impact velocity, and the $x$-ray tubes were independently triggered from the second magnetic velocity coil. The x-ray film cassette, using Kodak Direct Exposure film backed by a Quanta Fast Detail screen, was stationed about $100 \mathrm{~mm}$ from the centerline of the debris trajectory. A representative test result performed on 304 stainless steel is shown in Figure 2. A shadow of the glass barrier plate is also observed in the first station radiograph. The fragment debris subsequently impacted an aluminum witness plate, which provided in some cases an independent measure of particle size and velocity statistics (Kipp, 1994). 


\section{Materials}

Elemental or alloyed metals from various sources were used in the present tests. Copper spheres were as-received OFHC material with a density of $9830 \mathrm{~kg} / \mathrm{m}^{3}$. Similarly, as-received 7075-T6 aluminum spheres with a density of $2800 \mathrm{~kg} / \mathrm{m}^{3}$ were tested. Several steels were studied: an AISI Type 304 chromium-nickel stainless steel; AF1410 and D6AC steels (provided by Morris Dilmore, Wright Laboratory, Eglin AFB, who also performed heat treatment on the sample spheres); and an unspecified steel, extracted and prepared from $7.6 \mathrm{~mm}$ armor piercing projectiles. A pure tantalum material, density of $16650 \mathrm{~kg} / \mathrm{m}^{3}$, was provided by David Lassila, Lawrence Livermore National Laboratory; shock wave properties on this tantalum are reported by Furnish, et al. (1994). The titanium-6\% Al-4\% Va, density of $4420 \mathrm{~kg} / \mathrm{m}^{3}$, was provided by Lalit Chhabildas, Sandia National Laboratories; spall and fragmentation properties of this metal are reported by Chhabildas, et al. (1990).

\section{EXPERIMENTAL TEST RESULTS}

An extensive experimental study testing the fragmentation properties of the selected metals was completed. Approximately 5 to 8 tests of the type illustrated in Figure 2 for stainless steel were completed for each metal. Radiographic records were analyzed to provide kinematic and statistical fragment size data. The actual radiographic data are too extensive to include in the present report but are available in a technical report (Grady and Kipp, 1996).

The nature of the debris dispersion illustrated by stainless steel in Figure 2 was generally exhibited by all metals tested, although in some cases more axial dispersion was noted, and for some materials a conical spray of fine particles was observed outward of, and trailing, the primary debris disc. The source of this conical spray was addressed in one computational study.

The radial expansion of the debris disc as a function of the input velocity was a principal observable used in analytic assessment of failure and fragmentation properties of the metals 
tested. These data are provided in Figure 3. Strain-to-failure data were also assessed from the radiographic records. These data are presented and analyzed in a later section (see Figure 9). Statistical fragmentation data used to determine dynamic fracture resistance properties are also considered in a later section.

The principal plate material used for each metal is reported in Table 1. For several metals tested, two plate materials were used before the optimum material, in terms of achieving a range of expansion velocities, was determined. For example, two tests with PMMA plates for copper and one for APR steel were performed before glass was selected as the preferred barrier material. These data are recognized as the low or zero expansion velocity points at the higher impact velocities in Figure 3. In a later section, the expansion velocity data for different plate materials are shown to coincide when plotted against the impact shock pressure. Several tests on tantalum with glass barrier material were performed before it was realized that the higher impedance aluminum oxide was necessary to exceed the fragmentation threshold of this metal.

\section{ANALYSIS}

An intuitive understanding of the sphere-on-plate impact event is achieved through consideration of the stress history at the first point of contact of the sphere and the plate on the central axis of impact. The on-axis pressure (or axial stress) is expected to look qualitatively as shown in Figure 4.

Characteristic pressure amplitudes and times in the profile are reasonably calculated from the geometry and kinematics of the event. The initial shock pressure $p_{h}$ (the Hugoniot pressure) at the interface, before curvature of the spherical interface is realized, is governed by the Hugoniot shock-wave conditions for the planar impact of the two solids, and is given by,

$$
p_{h}=\frac{Z_{S} Z_{T}}{Z_{S}+Z_{T}} V_{I} \text {, }
$$


where $V_{I}$ is the impact velocity, while $Z_{S}$ and $Z_{T}$ are the mechanical shock impedances of sample and target materials, respectively. The mechanical impedance, $Z=\rho c$, is the product of the density and a wave speed which is, to first order, the acoustic wave velocity, and for more accurate estimates, the amplitude dependent shock velocity.

The Hugoniot pressure is maintained at this interface through a time duration $\tau_{1}$, which is governed by the arrival of pressure release waves from the diverging spherical surface of the sphere. Subsequently the central interface pressure drops rapidly to a value of the order of the hydrodynamic Bernoulli pressure. Further release of the pressure occurs at time $\tau_{2}$, when pressure waves reach the back free surface of the target plate either through the reflected shock or through emergence of the stagnation pressure profile for somewhat thicker plates. Note that for very thin plates $\tau_{2}$ can be less than $\tau_{1}$.

\section{Coupling of the Impact Shock Energy}

Early in the impact event, shock energy is coupled into the spherical sample. The shock pressure does work on the sphere from the instant of impact up to time $\tau_{1}$ which completes the shock coupling phase. There is reasonably compelling evidence that this shock energy is largely responsible for fragmentation of the spherical sample (Kipp, et al., 1993; Grady and Kipp, 1995).

The magnitude of this energy can be estimated through consideration of a model of the shock coupling process during the normal impact of a spherical projectile on a planar surface. The model was originally pursued by Ang (1990) to evaluate jetting at the impact interface. It was subsequently extended to processes of shock energy coupling and fragmentation (Kipp, et al., 1993; Grady and Kipp, 1995). The present discussion extracts further results important to the shock energy coupling process.

The contact process during impact is illustrated in Figure 5. The sphere of radius $R$ impacts a surface at a velocity $V_{I}$. A circular region of contact at radius $a$ propagates outward from the 
initial point of impact and is initially supersonic, but slows rapidly as the spherical surface curves away from the target plane. This contact circle transitions from supersonic to subsonic velocity at a radius $a_{c}$, which determines the maximum area of shock coupling into the sphere. Release waves then propagate toward the central axis, quenching the shock coupling phase $\left(\tau_{1}\right.$ in Figure 4).

From the geometry of the event it has been shown (Kipp, et al., 1993; Grady and Kipp, 1995),

$$
\begin{gathered}
a_{c}=V_{I} t_{c} \sqrt{\frac{2 R}{V_{I} t_{c}}-1}, \\
c=\frac{V_{I}\left(\frac{R}{V_{I} t_{c}}-1\right)}{\sqrt{\frac{2 R}{V_{I} t_{c}}-1}},
\end{gathered}
$$

provide conditions for the radius $a_{c}$ of the shock coupling disc and its development time $t_{c}$.

Identifying the nondimensional parameters $U=V_{I} / c, A_{c}=a_{c} / R$ and $T_{c}=c t_{c} / R$ one obtains the solutions,

$$
\begin{gathered}
A_{c}=\frac{a_{c}}{R}=\frac{U}{\sqrt{U^{2}+1}} \\
T_{c}=\frac{c t_{c}}{R}=\frac{1}{U}\left(1-\frac{1}{\sqrt{U^{2}+1}}\right) .
\end{gathered}
$$

The time $t_{c}$ (or $T_{c}$ ) determines the time of propagation of the contact circle to the maximum radius of supersonic motion. Shock coupling continues through the duration of lateral release wave propagation to the central axis, which requires an additional time $t_{r}=a_{c} / c$. The total shock coupling duration $t_{s c}=t_{c}+t_{r}$ is found to be, 


$$
T_{s c}=\frac{c}{R}\left(t_{c}+t_{r}\right)=\frac{1}{U}\left(1+\frac{U^{2}-1}{\sqrt{U^{2}+1}}\right)
$$

Shock energy is coupled into the spherical sample during the period of growth of the contact disc and is completed when lateral release waves reach the central axis. The coupled shock energy can be calculated from the work on the contact interface over the coupling time $t_{s c}$ and is generally,

$$
E_{s}=2 \pi \int_{0}^{a_{c} t_{s c}} \frac{p^{2}}{\rho c} \xi d \xi d t
$$

This will be approximated by,

$$
E_{s}=\alpha \frac{p^{2}}{\rho c} a_{c}^{2} t_{s c}
$$

where $\alpha$ is a constant which accounts for the loading time variation with radius over the contact disc. It is reasonable to assume an ellipsoidal shock volume (Kipp, et al., 1993; Grady and Kipp, 1995) in which case $\alpha=2 \pi / 3$.

The previous equations show that total shock energy coupled into the sphere as impact velocity increases depends on both the shock amplitude and on the extent of the shock coupling disc. Figure 6 illustrates the increase in contact disc radius, shock coupling duration and shock energy. Shock energy is normalized by the limiting shock energy as $V / c \rightarrow \infty$; namely,

$$
E_{\text {limit }}=\frac{2 \pi}{3} \frac{p^{2}}{\rho c^{2}} R^{3}
$$

Dashed lines indicate the small $V / c$ limit in which both $a_{c}$ and $t_{s c}$ increase linearly with impact velocity, and the coupled shock volume, $-a_{c}^{2} t_{s c}$, increases as the cube of the velocity. Since 
energy density increases with the square of the impact velocity, the total shock energy in the low velocity limit will increase as the fifth power of the velocity.

Several changes to the relation for the shock energy coupled into the spherical sample in Equation 8 can be made to improve the estimate. First, at impact velocities sufficient to fail and fracture metal samples, shock pressure amplitudes in the range of tens of GPa are achieved. The nonlinear compression of solids at these stresses are better accounted for by replacing the wave speed $c$ in Equation 8 with the shock velocity $U_{s}$ (Kipp, et al., 1993; Grady and Kipp, 1995). Second, in the earlier analysis leading to Equation 8, it was tacitly assumed that the shock coupling duration is controlled by the wave speed in the sphere material. If the sphere and plate materials are different, it is more likely that decoupling will be controlled by the higher wave speed material. Again, Equation 8 would apply, provided care is taken to use the correct wave speeds (Kipp, et al., 1993; Grady and Kipp, 1995).

Earlier studies (Kipp, et al., 1993; Grady and Kipp, 1995) have indicated that this prompt shock energy is principally responsible for the fragmentation and radial dispersal of the spherical sample. Thus estimates of the coupled shock energy at an impact velocity corresponding to the breakup threshold should provide a measure of the energy requirement to achieve failure under the present mode of deformation. This estimate has been made for the present data using Equation 8, accounting for finite amplitude shock compression as discussed earlier. These data are provided in Table 1. The shock energy $E_{s}$ at threshold which is absorbed in the spherical sample without fracture will be identified as $W_{p}$. In Table $1 w_{p}=W_{p} / m$ where $m$ is the mass of the sphere. The threshold impact velocity $V_{c}$ is obtained from the expansion velocity versus impact velocity plots from the previous section and the threshold shock pressure from the normal shock impedance solution (Equation 1). Shock velocities under the threshold impact conditions for both sphere and target plate material are provided in Table 1. Shock energy estimates, based on shock decoupling controlled by each wave velocity, are provided in the last column (sphere 
material left - plate material right). It is expected that the lower value, based on decoupling governed by the higher wave speed material, would be preferred.

\section{Critical Failure Energy from an Energy Balance Approach}

An alternative method for evaluating the critical energy needed to induce incipient sample (projectile) breakup has also been pursued. The method works directly with the expansion velocity data plotted for each material in the earlier section. The viability of this critical energy as a material failure property will be explored.

With reasonable generality it can be stated that the shock energy input to the spherical specimen on impact can be decomposed into the kinetic energy $T$ imparted to the sphere (here we regard the sphere initially at rest subject to impact by the plate at velocity $V_{I}$ ) and the energy of dissipation $W$ absorbed by the sphere through several processes, $E=T+W$. The kinetic energy readily decomposes into the center-of-mass kinetic energy and the longitudinal and radial expansion components relative to the center of mass, $T=T_{c m}+T_{\text {long }}+T_{\text {rad }}$.

It is experimentally observed that the longitudinal expansion component is small - hence the pancake shape assumed by the resulting debris clouds in the radiographic records. The center of mass kinetic energy imparted to the samples is not small, as is evidenced by the axial velocity change in the experimental radiographs. However, it can be shown that the axial impulse (and kinetic energy) imparted to the sphere during shock coupling is small. Most of the momentum exchange occurs during the later Bernoulli penetration.

The important dissipative terms appear to be those due to plasticity, shock heating and new fracture surface, $W=W_{p}+W_{h}+W_{f}$. Within the range of interest, dissipation due to shock heating, $W_{h}$, and fracture, $W_{f}$, can be ignored relative to the plastic work, $W_{p}$. 
Thus to a reasonable approximation, in the sphere-on-plate impact experiment, the impact shock energy is assumed to distributed between the plastic work expended in achieving failure and the radial expansion kinetic energy of the resulting debris fragments.

$$
E_{s}=W_{p}+T_{r a d}
$$

At this point it is necessary to make an assumption relating the input shock energy to the impact intensity. We make the reasonable assumption that the input energy $E_{s}$ is proportional to the square of the shock pressure $p$. In the previous analysis, detailed assumptions regarding the shock coupling process led to the $E_{s} \propto p^{2} \tau$ relationship illustrated in Equation 8. Here we are ignoring possible variations in coupling time - assuming instead that the coupling time is governed by the intrinsic characteristic time of the spherical sample $\tau \propto R / c$. As partial justification, expansion velocity data for copper and one steel, in which two different barrier materials (PMMA and glass) were used, are plotted against the calculated shock pressure (Equation 1) in Figure 7. The shock pressures reasonably normalize these data.

We then write this proportionality as $E_{s}=A\left(p / p_{c}\right)^{2}$, and Equation 10 becomes,

$$
T_{\text {rad }}=A\left(\frac{p}{p_{c}}\right)^{2}-W_{p}
$$

$A$ is the proportionality constant, and since $T_{r a d}=0$ at $p=p_{c}$,

$$
T_{\text {rad }}=W_{p}\left[\left(\frac{p}{p_{c}}\right)^{2}-1\right]
$$

Experimental evidence indicates that the debris in a sphere-on-plate impact expands as a reasonably uniform disc of fragments, in which case the radial kinetic energy is related to the expansion velocity through $T_{r a d}=m v_{e x}^{2} / 4$. If a material constant $v_{c}$ is defined through $W_{p}=m v_{c}^{2} / 2$, then Equation 12 can be written, 


$$
\frac{v_{e x}}{v_{c}}=\sqrt{2} \sqrt{\left(\frac{p}{p_{c}}\right)^{2}-1}
$$

Equation 13, based on reasonable assumptions regarding partitioning of energy in the present sphere-on-plate impact experiments, provides an expression for normalizing the expansion velocity data to a single plot. The two constants $v_{c}$ and $p_{c}$, within this representation, are sufficient to characterize a specific material. The constant $v_{c}$, or its equivalent $W_{p}$, is believed to be a useful material constant. The latter provides the magnitude of plastic work that the test sample can absorb before incipient fragmentation occurs. ( $v_{c}$ is conceptually useful in identifying the impact velocity at which, on impacting a rigid barrier, the kinetic energy will be absorbed in plastic work without fragmentation.) The parameter $p_{c}$ appears to relate to the shock impedance of the test material and its ability to couple a given magnitude of shock energy at a specific impact velocity.

Experimental data for the metals tested to date have been fit to the functional expression provided in Equation 13. Relevant parameters are provided in Table 1 and representative data for several of the materials are plotted in Figure 8 to examine the universality of Equation 13. Critical pressures in the two analysis methods differ because of the different methods of curve fitting the data.

\section{Assessment of the Two Methods for determining Threshold Failure Energy}

Two methods for estimating the threshold breakup energy from the experimental data have been explored. In the first, a model of the shock coupling process is developed, and the threshold impact velocity is used to calculate the energy from the resulting relations. Threshold energies are provided in Table 1. The lower value based on the fastest release wave velocity is believed to be the most reasonable.

Threshold energy values based on a second method, assuming a specific relationship between the energy and the impact shock pressure, are also provided in Table 1 . In general the trends are in 
agreement, although discrepancies of as much as a factor of three are noted - the second method providing the lower values.

The linear plot of the squared expansion velocity and shock pressure expected from Equation 13 is reasonably observed in some cases, but not as well in others. The trend when there is a discrepancy is to achieve a higher expansion velocity at a given impact pressure, indicating that the assumption of a constant shock coupling time may not be appropriate. This behavior is consistent with the analysis in the first method.

Threshold energies determined by the first method are believed to be most representative. At present the most useful approach may be to work directly with the models and computational codes to adjust failure model properties.

\section{Strain to Failure Data}

Experiments performed at impact amplitudes below the breakup threshold lead to test samples that are severely strained but not fragmented. The spherical samples are flattened and radially expanded due to the impact-induced impulse. For the softer metals - aluminum, copper, tantalum, and titanium - substantially more flattening is observed on the impact side. For the steels, a more symmetric (elliptic) distortion is observed.

As an operational measure of the induced strain, the fractional change in the axial dimension was determined, $\varepsilon=1-l / 2 R$, where $l$ is the reduced dimension of the sphere of initial radius $R$ (see Figure 9). To provide a measure of the critical strain $\varepsilon_{c}$ that the sample can sustain before breakup, strain values are plotted against impact pressure and linearly extrapolated to the threshold pressure at fragmentation as shown in Figure 9. Although there is no theoretical justification for this particular extrapolation, strain values are sufficiently close to critical conditions in most cases that large uncertainties are not expected. The data for D6AC steel, in 
which three tests were conducted at different subcritical pressures, provide the best indication of the trend.

Data in the plot of Figure 9 show strain-to-failure values ranging from about 0.08 for the ball bearing steel to greater than 0.40 for aluminum and copper. Tantalum, which is not shown in the plot, sustained a deformation strain close to 1.0 without fragmentation. Strain-to-failure data for the metals tested are provided in Table 1.

\section{Fragmentation Properties}

As observed in the radiographic data provided earlier, an indication of the extent of fragmentation (fragment number or statistical fragment size) can be obtained when impact conditions exceed the breakup threshold. Methods for quantifying the statistical fragment size and extracting fragmentation resistance material property data have been discussed in previous reports (Kipp, et al., 1993; Grady and Kipp, 1995). These methods are described here with some additional analysis, and used to provide fragmentation resistance property data for the metals tested in this work.

The method used for extracting fragment number and average fragment size data from radiographs of reasonable tightly packed fragment debris clouds is based on a statistical formula for randomly positioned areas (Johnson and Mehl, 1939). The statistical approach leads to a relation between the observed area $A_{o b s}$ and the actual area $A$ of overlapping objects placed at random on a region $A_{\text {reg }}$,

$$
A=A_{o b s} \ln (1-f)^{-1 / f}
$$

where $f=A_{o b s} / A_{\text {reg }}$ is the fraction of the region covered. A Taylor expansion of Equation 14 reveals that $A$ is always greater than $A_{o b s}$ and approaches $A_{o b s}$ as $f$ becomes small. 
Application of the statistical relation in Equation 14 to radiographs of fragment debris is reasonably clear. Because of shadowing and overlap of fragments in the relatively dense debris cloud, the fragment area projected on the radiographic image will be less than the projected area of the same fragments if shadowing and overlap does not occur. Thus, image processing of the radiographic record requires two measured properties - the total observed projected fragment area $A_{o b s}$, and an estimate of the area fraction of the debris cloud region masked by the debris fragments. Assuming a random distribution of fragments through the region, Equation 14 provides the required projected fragment area. Note that if $f$ is reasonably small, the expression for $A$ is relatively insensitive to inaccuracies in $f$.

Knowing the total volume of fragmented material within the debris cloud, the number of fragments $N$ and a statistical measure of the fragment size $S$ can be determined. The method to be described differs from that used in earlier reports (Kipp, et al., 1993; Grady and Kipp, 1995) and is believed to be an improved use of the data. The new technique leads to somewhat larger statistical fragment sizes than the earlier method.

The assumptions are made that fragments in the collection of particles are nominally spherical in shape and that the distribution in size is described by the exponential distribution,

$$
N=N_{o} e^{-m / \mu}
$$

The exponential distribution is based on a uniform strain rate random fragmentation of the sphere of mass $M$ into $N_{o}$ fragments of average fragment mass $\mu$ (Grady and Kipp, 1985). The number of fragments of mass $m$ within a differential range $d m$ is

$$
d N=\frac{N_{o}}{\mu} e^{-m / \mu} d m
$$


If the projected area (radiograph silhouette) of a fragment is $a$, then the total projected area of fragments in this size range is $d A=a d N$, which can be integrated over the full range of particles sizes to provide,

$$
A=N_{o}\left(\frac{3 \sqrt{\pi} \mu}{4 \rho}\right)^{2 / 3}
$$

The mass of the initial spherical sample, the total number of fragments and the mean fragment mass are related through $M=N_{o} \mu$. Relating size and mass of the average fragment through $\mu=\pi \rho s^{3} / 6$ one obtains the result for the average fragment size,

$$
S=\frac{3}{2} \frac{M}{\rho A}
$$

From an individual radiograph of the fragment debris, the projected fragment area $A$ is determined from the record and Equation 14, and then the statistical fragment size $S$ is determined through Equation 18. A strain rate at failure is calculated by dividing the radial expansion velocity by the initial radius of the sphere, $\dot{\varepsilon}=v_{e x} / R$. A dynamic toughness is then calculated based on the strain rate and the average fragment size through the relation,

$$
K_{f}=\frac{\rho c \dot{\varepsilon} S^{3 / 2}}{\sqrt{24}}
$$

Equation 19, which relates a measure of the dynamic fragmentation toughness to fragment size and expansion strain rate, has been developed in an energy-based theory of dynamic fragmentation of solids (Grady, 1988).

The technique outlined above has been used to provide values for the dynamic fragmentation toughness for the metals investigated in the present study. These results are provided in Table 2 . 


\section{NUMERICAL INVESTIGATION}

Numerical techniques to model fracture and fragmentation have been reported by Kipp, et al. (1993a, 1993b) and Grady and Kipp (1994) for Eulerian code applications, and by Johnson, et al. (1990) for Lagrangian code applications. In these cases, the primary theory of fragmentation is that described by Grady (1988), in which the average fragment dimension is related to the strain rate and temperature at the time of tensile fracture. If the measure of fragment size calculated for each locality in an inhomogeneous region is assumed to represent the average of a Poisson distribution, then the sum of these distributions provides an overall fragment size distribution for the fragmented solid (Kipp, et al., 1993a, 1993b). Also relevant to the present study is an extensive series of experiments and accompanying analyses reported for a hardened steel by Kipp, et al. (1993a, 1993b), and a further study by Grady and Kipp (1994) in which copper spheres were made to impact a hardened steel target plate of thickness comparable to the copper ball diameter. Other approaches to numerically simulate impact fragmentation of materials with damage models have been reported by Melosh, et al. (1992) and Fahrenthold and Yew (1995). Smoothed particle hydrodynamics techniques have also been used to model fragmentation (e.g., Stellingwerf and Wingate, 1993; Randles, et al., 1995; Mandell, 1996); discrete fragments that are formed as part of the fracture process can be tracked to late times (Mandell, 1996).

The conditions for fragmentation are influenced by the fracture model used in the codes; some regions may experience release wave interactions that lead to traditional spall (large confining pressure, high strain rates), and other regions expand more slowly to fail in unconfined expansion. The sphere impacts described in this report have contributions to failure by both mechanisms. Consequently, the fracture model must be able to accommodate a spectrum of failure situations, and to accurately define the failure conditions to be used in the fragmentation theory for local average fragment size. 
The code used for the analyses reported here is CTH (McGlaun, et al., 1990; Hertel, et al., 1993), an Eulerian wave propagation code. The equation of state for both the aluminum and PMMA was Mie-Gruneisen, with a linear shock velocity - particle velocity representation of the shock Hugoniot (for these materials, 7075-T6 aluminum and PMMA, respectively, the reference densities are 2804 and $1186 \mathrm{~kg} / \mathrm{m}^{3}$, the bulk sound speeds are 5200 and $2598 \mathrm{~m} / \mathrm{s}$, the slopes of the linear shock - particle velocity fits are 1.360 and 1.516, and the Gruneisen constants are 2.20 and 0.97). The material strength was modeled with the Steinberg (1996) plasticity model, from which a measure of the equivalent plastic strain could be obtained for comparison to the experimentally determined values. The initial yield strengths of both these materials were taken to be $0.42 \mathrm{GPa}$, with the aluminum strain hardening to $0.81 \mathrm{GPa}$ (Steinberg, 1996); the Poisson ratios are 0.33 (aluminum) and 0.37 (PMMA). The fracture model used here is that of Johnson and Cook (1985), in which a failure strain, $\varepsilon^{\mathrm{f}}$, is accumulated whereby both spall and extensional fracture can be represented. Spall strengths were set at $1.5 \mathrm{GPa}$ (aluminum) and $0.15 \mathrm{GPa}$ (PMMA). During a calculation, an ancillary file is written that contains the strain rate, temperature, and mass at the time of fracture for each cell; this file is evaluated in a postprocessing mode to define the fragment size characteristics of an event. Axial symmetry is appropriate for the normal impact of a sphere onto a flat target; a uniform resolution of $0.05 \mathrm{~mm}$ square cells was used in the calculations reported here.

Two aluminum sphere impact cases are used to illustrate the approach taken in the numerical analyses: a non-fragmenting (subcritical) impact $(2230 \mathrm{~m} / \mathrm{s}$ onto $2.92 \mathrm{~mm}$ PMMA), and a fragmenting impact ( $3920 \mathrm{~m} / \mathrm{s}$ onto $2.92 \mathrm{~mm}$ PMMA). The calculated velocity decrement for the subcritical impact was $310 \mathrm{~m} / \mathrm{s}$ resulting in a residual velocity of $1920 \mathrm{~m} / \mathrm{s}$, which is within $2 \%$ of the experimentally determined residual velocity of $1880 \mathrm{~m} / \mathrm{s}$. For this impact, the pressure at the contact point is $9 \mathrm{GPa}$, which decays nearly linearly in transit through the sphere to an amplitude of $1 \mathrm{GPa}$ near the trailing surface of the sphere; the transit time is about $1.2 \mu$ s. The calculated velocity decrement for the fragmenting impact was $650 \mathrm{~m} / \mathrm{s}$, resulting in a residual velocity of 
$3270 \mathrm{~m} / \mathrm{s}$, which is within $1 \%$ of the experimentally determined residual velocity of $3310 \mathrm{~m} / \mathrm{s}$. For this higher velocity impact, the pressure at the contact point is nearly $20 \mathrm{GPa}$, which also decays nearly linearly during transit through the sphere to an amplitude of $1 \mathrm{GPa}$ near the trailing surface of the sphere; the transit time is about $1 \mu \mathrm{s}$.

The final deformation of the aluminum sphere calculated for the subcritical impact velocity $(2230 \mathrm{~m} / \mathrm{s})$ is shown in Figure 10a, accompanied by the experimental result, Figure 10b. (The diameter of the deformed experimental sphere is $7.7 \mathrm{~mm}$.) Fringes have formed on the periphery of the simulation that do not appear in the experimental radiograph, and the impacted surface is slightly more flattened in the calculation than in the radiograph. A calculated value of the strain measure, $\varepsilon=1-l / 2 R$, is 0.47 , which is considerably larger than the strain value of 0.22 obtained from the radiograph for this particular experiment (Figure 10b), but quite close to the critical experimental value of 0.42 (Table 1). The calculation required an elapsed time of $20 \mu \mathrm{s}$ before the total equivalent plastic strain for the aluminum reached a steady amplitude of about 0.9 (obtained by mass weighting the equivalent plastic strain summed over all aluminum cells). Although this value is much larger than the experimental value, there is a substantial plastic strain in the fringe material; when the total equivalent plastic strain is determined from the main part of the deformed sphere, the value is about 0.52 , which is consistent with the calculated value using the strain measure based on the permanent axial deformation. In contrast to the long time to equilibrium for the plastic strain, the change in axial (average) velocity is complete by about $4 \mu \mathrm{s}$ after impact. It should also be noted that the calculation indicates the formation of damage within the deformed aluminum sphere (Figure 10a), structure not discernible in the radiograph; hence the threshold impact velocity needs to be primarily associated with the onset of fragmentation, since the sphere in a subcritical impact may in fact sustain severe internal damage, but retain sufficient overall integrity to hold all its mass together in a unit that has no radial expansion velocity. 
The calculation for the aluminum sphere impact at the higher velocity $(3920 \mathrm{~m} / \mathrm{s})$ results in nearly complete fragmentation of the aluminum. The velocity attributes of tracer particles located in the aluminum are utilized to convect their locations from $9 \mu \mathrm{s}$, the time at which the calculation was terminated, to $53 \mu \mathrm{s}$ (Figure 10c), a time corresponding to an experimental radiograph at the first image position (Figure 10d). The diameter of the primary cloud of fragments in the radiograph (Figure 10d) is about $37 \mathrm{~mm}$. The tracer locations appear to be more dispersed both radially and axially than the radiographic image indicates, although the central five main clusters of tracers, which comprise $80 \%$ of the aluminum sphere mass, have a radial dimension which is similar to the experiment (Figures 10c and 10d); the calculated radial expansion velocity of this envelope is about $290 \mathrm{~m} / \mathrm{s}$, which compares well with the measured expansion velocity for this experiment of $281 \mathrm{~m} / \mathrm{s}$. The calculated radial expansion velocity of the outer dispersed material is in excess of $500 \mathrm{~m} / \mathrm{s}$. The average fragment size determined from the cell-by-cell fragmentation analysis is about $0.7 \mathrm{~mm}$, in which a fracture toughness value of $23 \mathrm{MPa} \mathrm{m}^{1 / 2}$ was used. The average strain rate determined from the calculation (by mass weighting the strain rate at the time of fracture summed over all aluminum cells) is about $6 \times 10^{5} \mathrm{~s}^{-1}$. In the particular experiment considered here for aluminum impact at $3920 \mathrm{~m} / \mathrm{s}$ onto $2.92 \mathrm{~mm}$ PMMA, an average expansion strain rate of $9 \times 10^{4} \mathrm{~s}^{-1}$ was obtained. Characteristic fragment sizes discernible on the radiographic images ranged from a minimum of $0.4 \mathrm{~mm}$ to a maximum of about $1.5 \mathrm{~mm}$. The numerical simulation includes fractures that have occurred by spallation as well as circumferential expansion; as spallation strain rates tend to be much larger than circumferential strain rates, the average strain rate in the aluminum determined numerically is expected to be larger than that obtained based on expansion alone, and the consequent average fragment sizes will be smaller.

\section{DISCLAIMER}

This report was prepared as an account of work sponsored by an agency of the United States Government. Neither the United States Government nor any agency thereof, nor any of their employees, makes any warranty, express or implied, or assumes any legal liability or responsibility for the accuracy, completeness, or usefulness of any information, apparatus, product, or process disclosed, or represents that its use would not infringe privately owned rights. Reference herein to any specific commercial product, process, or service by trade name, trademark, manufacturer, or otherwise does not necessarily constitute or imply its endorsement, recommendation, or favoring by the United States Government or any agency thereof. The views and opinions of authors expressed herein do not necessarily state or reflect those of the United States Government or any agency thereof. 


\section{SUMMARY}

This experimental fracture material property test method to evaluate dynamic fragmentation provides a means for discerning fragmentation thresholds and determining an average measure of the fracture toughness. These experimental data also provide a standard for numerical simulation evaluation. The current simulations capture the axial velocity changes accurately, but overpredict both the deformation of the unfragmented sphere and the dispersion of the debris for the fragmenting case discussed. Average fragment sizes determined with the simulations appear to be smaller than the dominant size observed in the radiographs, but further detailed analysis of the radiographic data and comparisons with computations need to be pursued.

\section{REFERENCES}

Ang, J. A., (1990) Impact Flash Jet Initiation Phenomenology, Int. J. Impact Engng, 10, 23-33.

Brown, W. K. (1989) Fragmentation of the Universe, J. Astrophys. Astr, 10, 89-112.

Chhabildas, L. C., L. M. Barker, J. R. Asay and T. G. Trucano, (1990) Spall Strength Measurements on Shock-Loaded Refractory Metals, Shock Compression of Condensed Matter - 1989, edited by Schmidt, et al., Elsevier Science Publishers, p. 429-432.

Englman, R., Z. Jaeger, and A. Levi (1984) Percolation Theoretical Treatment of Two-Dimensional Fragmentation in Solids, Phil. Mag. B, 50, 307-315.

Fahrenthold, E. P. and C. H. Yew (1995) Hydrocode Simulation of Hypervelocity Impact Fragmentation, Int. J. Impact Engng, 17, 303-310.

Furnish, M. D., L. C. Chhabildas, and D. J. Steinberg (1994) Dynamic Behavior of Tantalum, High Pressure Science and Technology - 1993, edited by S. C. Schmidt, et al., Am. Inst. Phys., 1849-1852.

Glenn, L. A. and A. Chudnovsky (1986) Strain Energy Effects on Dynamic Fragmentation, J. Appl. Phys., 포, 1379-1380.

Grady, D. E. (1982) Local Inertia Effects in Dynamic Fragmentation, J. Appl. Phys., $\underline{53}$, 322-325.

Grady, D. E. (1988) The Spall Strength of Condensed Matter, J. Mech. Phys. Solids, $\underline{36}, 353-384$.

Grady, D. E. (1990) Particle Size Statistics in Dynamic Fragmentation, J.Appl. Phys., 68, 6099-6105.

Grady, D. E. and M. E. Kipp (1995) Experimental Measurement of Dynamic Failure and Fragmentation Properties of Metals, Int. J. Solids Structures, 32, 2779-2792. 
Grady, D. E. and M. E. Kipp (1996) Impact Failure and Fragmentation Properties of Metals, Sandia National Laboratories Report. (in preparation).

Hertel, E. S., et al. (1993) CTH: A Software Family for Multi-Dimensional Shock Physics Analysis, Proceedings of the 19th International Symposium on Shock Waves, Volume 1, 377-382, Edited by R. Brun and L. D. Dumitrescu, Marseille, France 26-30 July 1993.

Johnson, W. A. and R. F. Mehl (1939) Reaction Kinetics in Processes of Nucleation and Growth, Trans. A. I. M. M. E., 135, 416-458.

Johnson, G. R. and W. H. Cook (1985) Fracture Characteristics of Three Metals Subjected to Various Strains, Strain Rates, Temperatures, and Pressures, Engng Fracture Mechanics, 21, 31-48.

Johnson, G. R., R. A. Stryk, T. J. Holmquist, and O. A. Souka (1990) Recent EPIC Code Developments for High Velocity Impact: 3D Element Arrangements and 2D Fragment Distributions, Int. J. Impact Engng., 10, 281-294.

Kipp, M. E. and D. E. Grady (1985) Dynamic Fracture Growth and Interaction in One Dimension, J. Mech. Phys. Solids, $\underline{33}, 399-415$.

Kipp, M. E., D. E. Grady and J. W. Swegle (1993a) Experimental and Numerical Studies of HighVelocity Impact Fragmentation, Sandia National Laboratories Report SAND93-0773, August.

Kipp, M. E., D. E. Grady, and J. W. Swegle (1993b) Numerical and Experimental Studies of High-Velocity Impact Fragmentation, Int. J. Impact Engng, 14, 427-438.

Kipp, M. E. (1994) Target Response to Debris Cloud Incidence, High Pressure Science and Technology - 1993, edited by S. C. Schmidt, et al., Am. Inst. Phys., 1849-1852.

Mandell, D. A. (1996) Personal communication.

McGlaun, J. M., S. L. Thompson, and M. G. Elrick (1990) CTH: A Three-Dimensional Shock Wave Physics Code, Int. J. Impact Engng, 10, 351-360.

Melosh, H. J., E. V. Ryan, and E. Asphaug (1992) Dynamic Fragmentation in Impacts: Hydrocode Simulation of Laboratory Impacts, J. Geophys. Res. - Planets, 97, No. E9.

Randles, P. W., T. C. Carney, L. D. Libersky, J. D. Renick, and A. G. Petschek (1995) Calculation of Oblique Impact and Fracture of Tungsten Cubes Using Smoothed Particle Hydrodynamics, Int. J. Impact Engng, 17, 661-672.

Steinberg, D. J. (1996) Equation of State and Strength Properties of Selected Materials, Lawrence Livermore National Laboratory Report UCRL-MA-106439, February 13.

Stellingwerf, R. F. and C. A. Wingate (1993) Impact Modeling with Smooth Particle Hydrodynamics, Int. J. Impact Engng, 14, 707-718. 
TABLES

Table 1

Failure Energies Based on Analytic Solution

\begin{tabular}{|c|c|c|c|c|c|c|c|c|c|c|c|}
\hline \multicolumn{4}{|c|}{ Experiment Configuration } & \multicolumn{4}{|c|}{$\begin{array}{c}\text { Shock Coupling } \\
\text { Analysis }\end{array}$} & \multicolumn{3}{|c|}{$\begin{array}{c}\text { Energy Balance } \\
\text { Analysis }\end{array}$} & \multirow[b]{2}{*}{$\varepsilon_{c}$} \\
\hline $\begin{array}{l}\text { Material } \\
\text { (Sphere) }\end{array}$ & $\begin{array}{l}\text { Material } \\
\text { (Plate) }\end{array}$ & $\begin{array}{l}\text { Density } \\
\left(\mathrm{kg} / \mathrm{m}^{3}\right)\end{array}$ & $\begin{array}{c}\mathrm{V}_{\mathrm{c}} \\
(\mathrm{m} / \mathrm{s})\end{array}$ & $\begin{array}{c}\mathrm{p}_{\mathrm{c}} \\
(\mathrm{GPa})\end{array}$ & $\begin{array}{c}\mathrm{U}_{\mathrm{s}} \\
\text { (Sphere) }\end{array}$ & $\begin{array}{c}\mathrm{U}_{\mathrm{s}} \\
\text { (Plate) }\end{array}$ & $\begin{array}{c}w_{p}^{2,3} \\
(J / g)\end{array}$ & $\begin{array}{c}\mathrm{p}_{\mathrm{c}} \\
(\mathrm{GPa})\end{array}$ & $\begin{array}{c}v_{c} \\
(\mathrm{~m} / \mathrm{s})\end{array}$ & $\begin{array}{l}w_{p}^{3} \\
(J / g)\end{array}$ & \\
\hline Aluminum & PMMA & 2800 & 2800 & 14 & 6260 & 5670 & $32-48$ & 16 & 199 & 19.8 & 0.42 \\
\hline Copper & Glass & 8930 & 3500 & 34 & 5060 & 5530 & $75-56$ & 38 & 250 & 31.7 & 0.45 \\
\hline Steel $(1)^{1}$ & PMMA & 7900 & 3100 & 21 & 5300 & 6570 & $23-12$ & 23 & 129 & 8.2 & 0.08 \\
\hline Steel $(2)^{1}$ & Glass & “ & 3650 & 36 & 5750 & 5690 & $70-66$ & 38 & 208 & 21.6 & 0.31 \\
\hline Steel (3) & Glass & " & 3600 & 35 & 5730 & 5640 & $66-63$ & 38 & 208 & 21.6 & 0.33 \\
\hline Steel $(4)^{1}$ & Glass & " & 2900 & 25 & 5440 & 4840 & $25-38$ & 28 & 124 & 7.7 & - \\
\hline Steel $(5)^{1}$ & Glass & “ & 3600 & 35 & 5730 & 5640 & $66-63$ & 36 & 222 & 24.6 & 0.38 \\
\hline Tantalum & Alumina & 16700 & 2950 & 80 & 4640 & 10300 & $124-9$ & 81 & 145 & 10.5 & 1.00 \\
\hline Titanium & Glass & 4520 & 2650 & 19 & 5850 & 4260 & $25-75$ & 21 & 160 & 12.8 & 0.23 \\
\hline \multicolumn{12}{|c|}{$\begin{array}{l}1 \text { Steels are respectively (1) E51200; (2) AF1410; (3) D6AC; (4) APR; (5) SS304. } \\
2 \text { Estimates on the left and the right are based on shock coupling time controlled by shock (and release) } \\
\text { velocities in sphere and plate material, respectively. } \\
{ }^{3} \mathrm{w}_{\mathrm{p}}=\mathrm{W}_{\mathrm{p}} / \mathrm{m} \text { where } \mathrm{W}_{\mathrm{p}} \text { is the threshold value of } \mathrm{E}_{\mathrm{s}} \text {. }\end{array}$} \\
\hline
\end{tabular}

Table 2

Fragmentation Toughness of Selected Metals

\begin{tabular}{|l|c||l|c|}
\hline \multicolumn{1}{|c|}{ Material } & $\begin{array}{c}\mathrm{K}_{\mathrm{f}} \\
\left(\mathrm{MPa} \mathrm{m}^{1 / 2}\right)\end{array}$ & \multicolumn{1}{|c|}{ Material } & $\begin{array}{c}\mathrm{K}_{\mathbf{f}} \\
\left(\mathrm{MPa} \mathrm{m}^{1 / 2}\right)\end{array}$ \\
\hline \hline E52100 Steel & $25-45$ & OFHC Copper & $50-80$ \\
\hline D6AC Steel & $85-105$ & 7075 Aluminum & $15-35$ \\
\hline AF1410 Steel & $85-105$ & 4Al6Va Titanium & $60-90$ \\
\hline SS304 Steel & $80-100$ & Tantalum & $10-30$ \\
\hline APR Steel & $55-75$ & & \\
\hline
\end{tabular}


FIGURES

Photographic

Plate

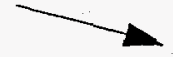

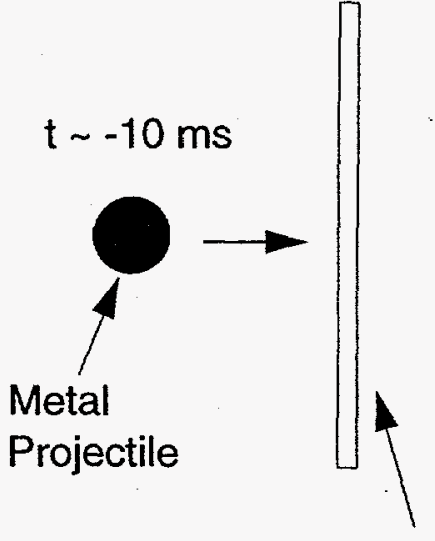

Barrier

Plate

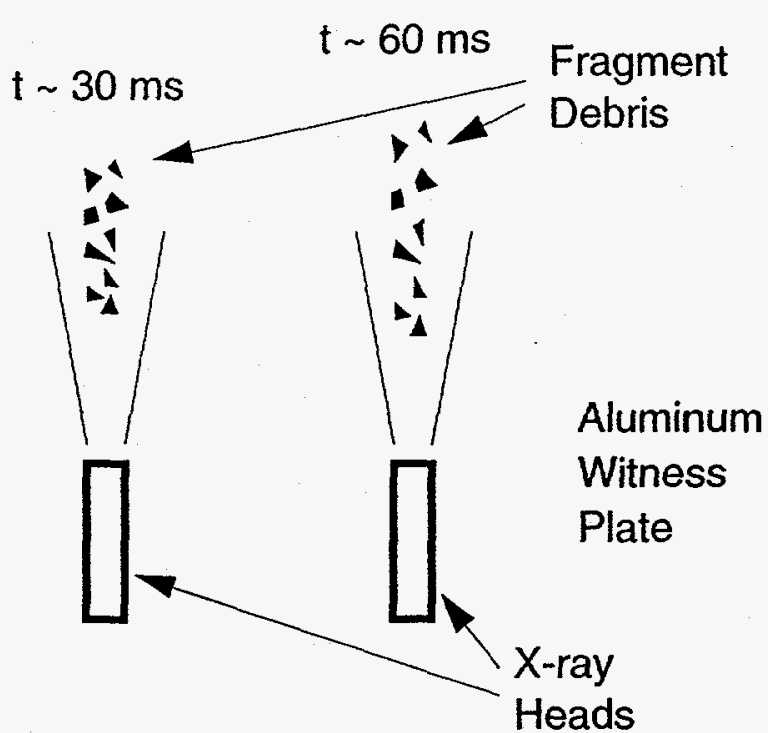

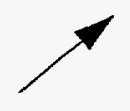

(1)

Figure 1. Experimental configuration for sphere-on-plate failure and fragmentation property tests.

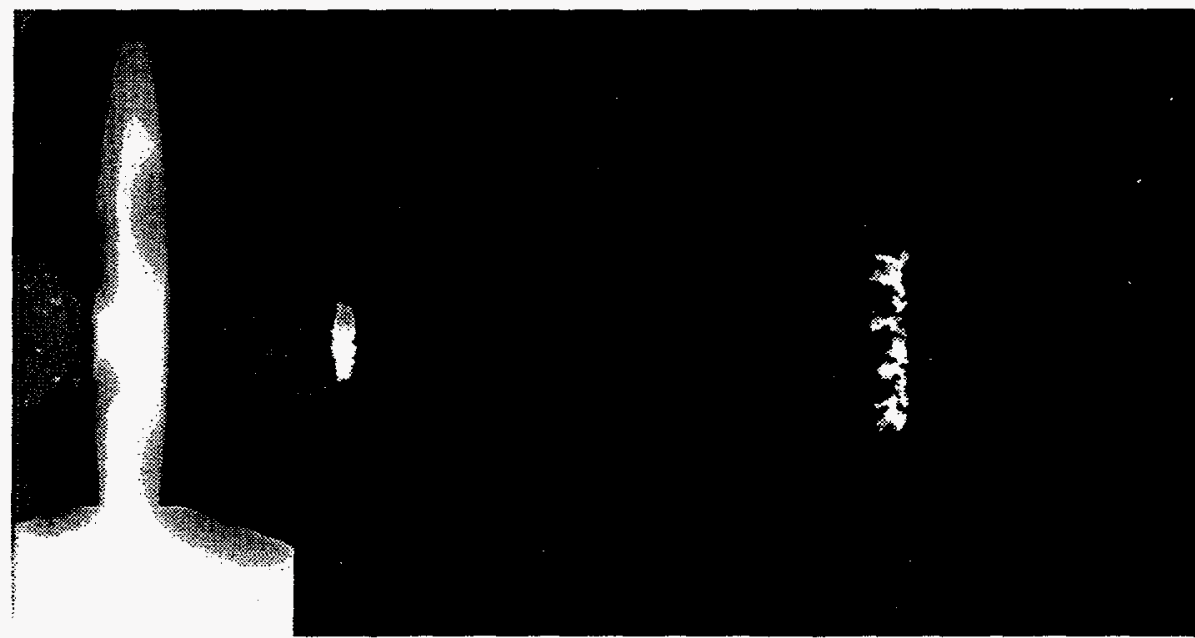

Figure 2. Example of radiographic images in test technique. Material is AISI Type 304 stainless steel. Target is $3.2 \mathrm{~mm}$ fused silica. Impact velocity is $4.1 \mathrm{~km} / \mathrm{s}$. 


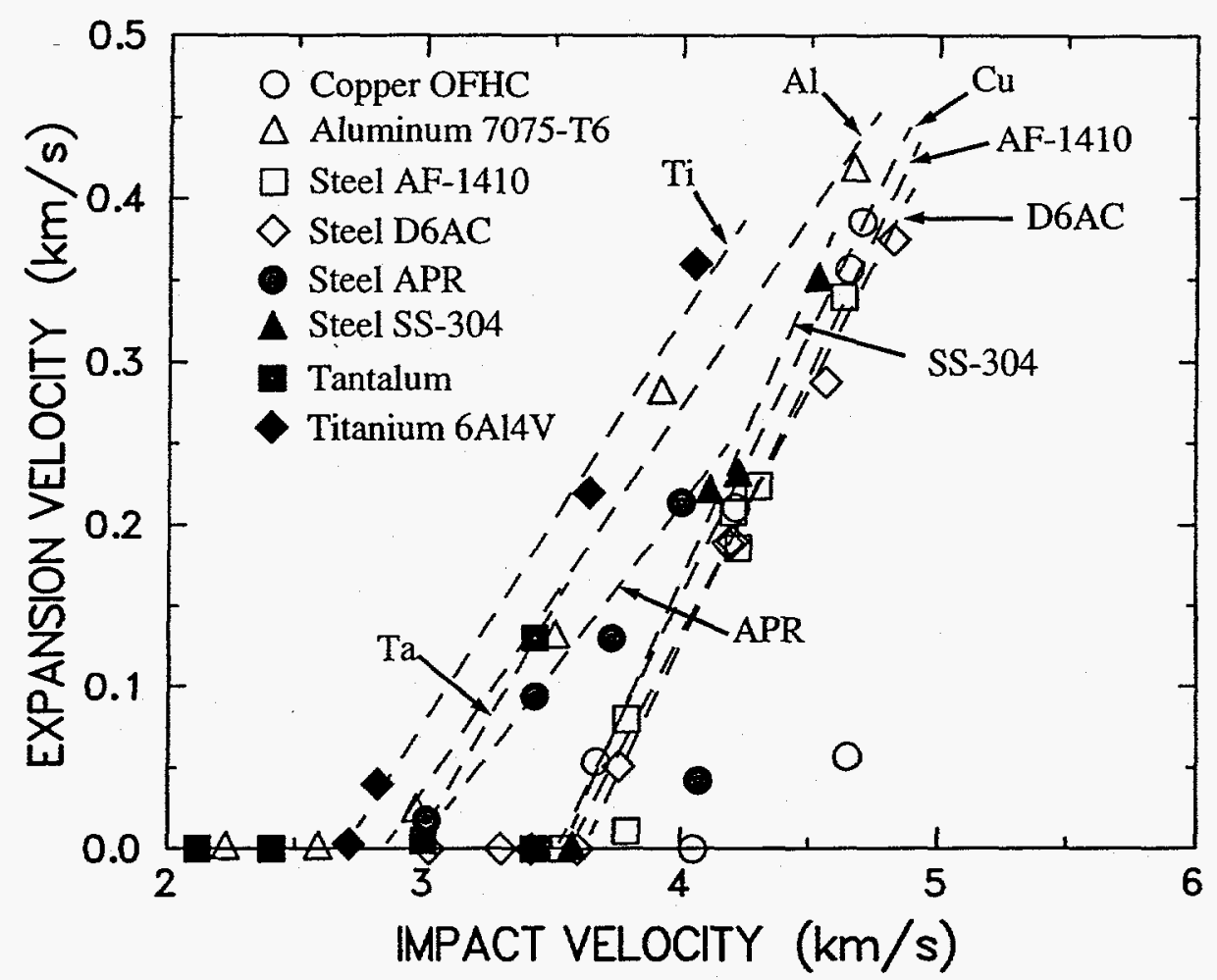

Figure 3. Expansion velocity versus impact velocity data from sphere impact tests for selected metals.
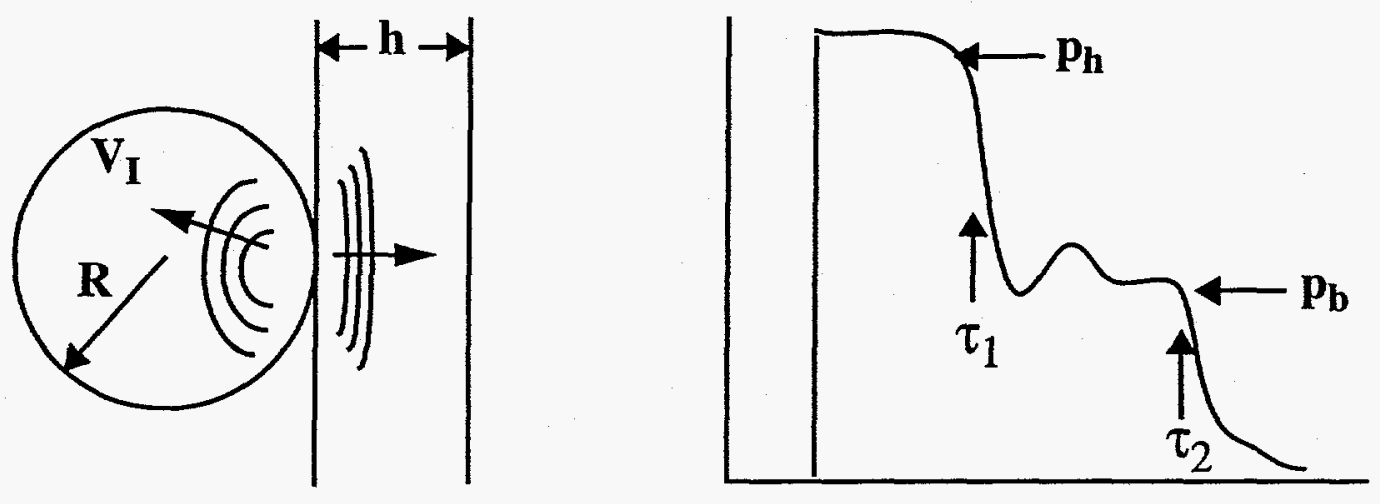

Figure 4. The qualitative pressure history at the central-axis impact interface identifying characteristic pressure amplitudes and times in the sphere-on-plate impact event. 


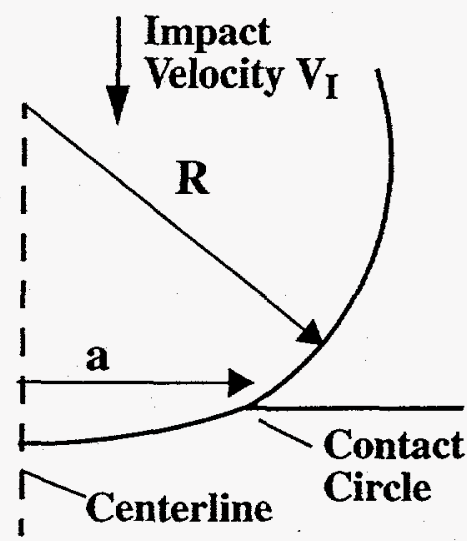

Figure 5. Contact process in the normal impact of a sphere on a planar surface.

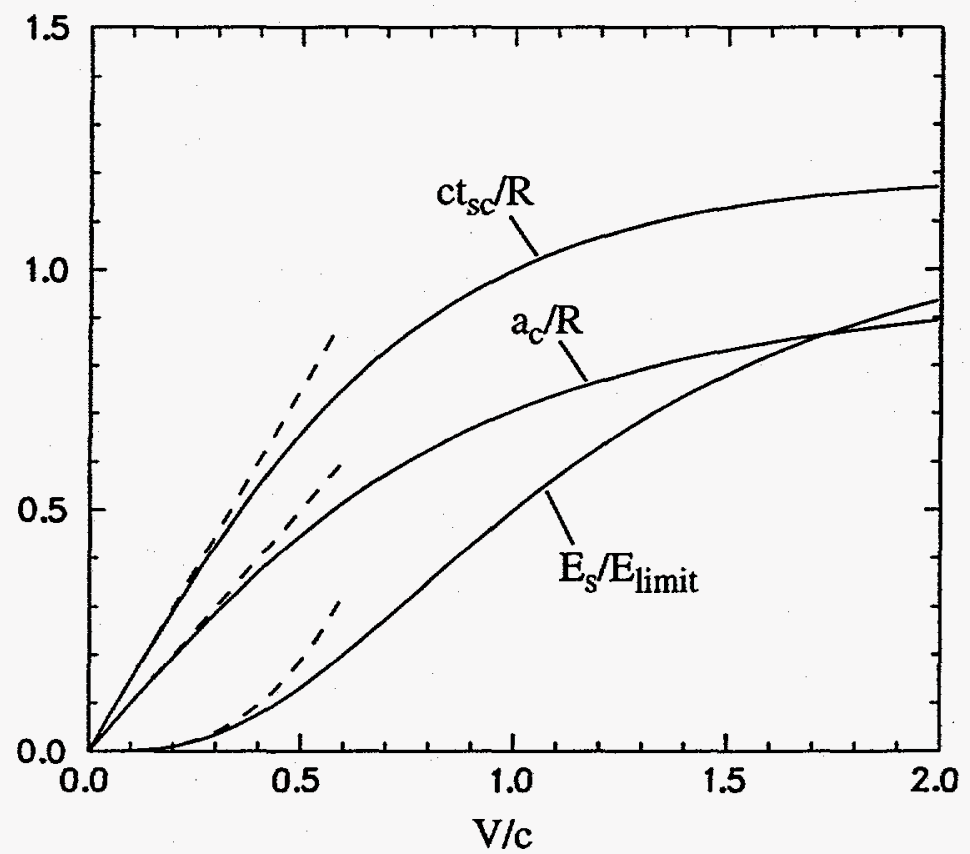

Figure 6. Variation of coupled shock energy and coupling parameters with the impact velocity (curves normalized to common ordinate). 


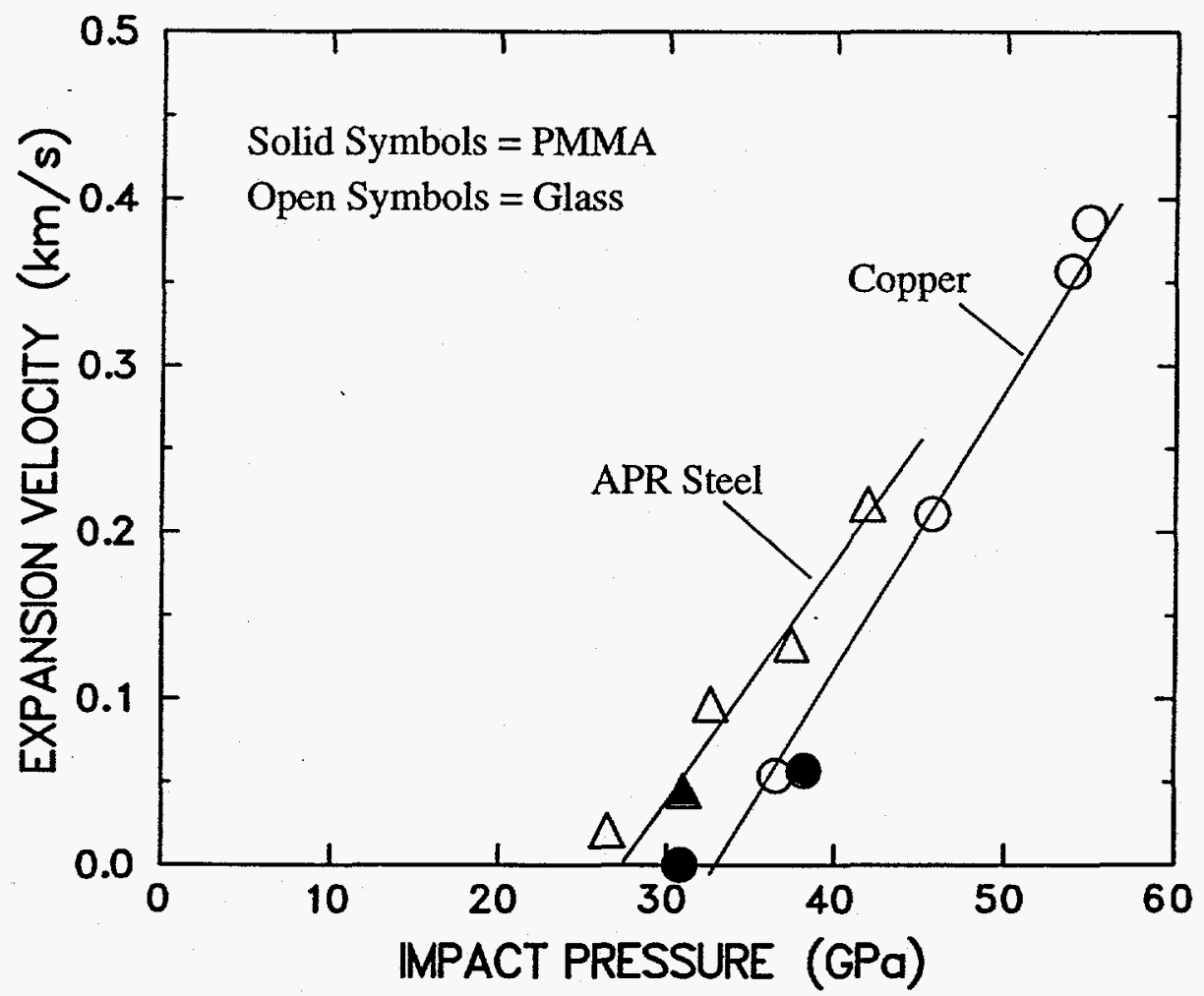

Figure 7. Expansion velocity plotted against impact shock pressure comparing impacts on PMMA and glass barrier plates.

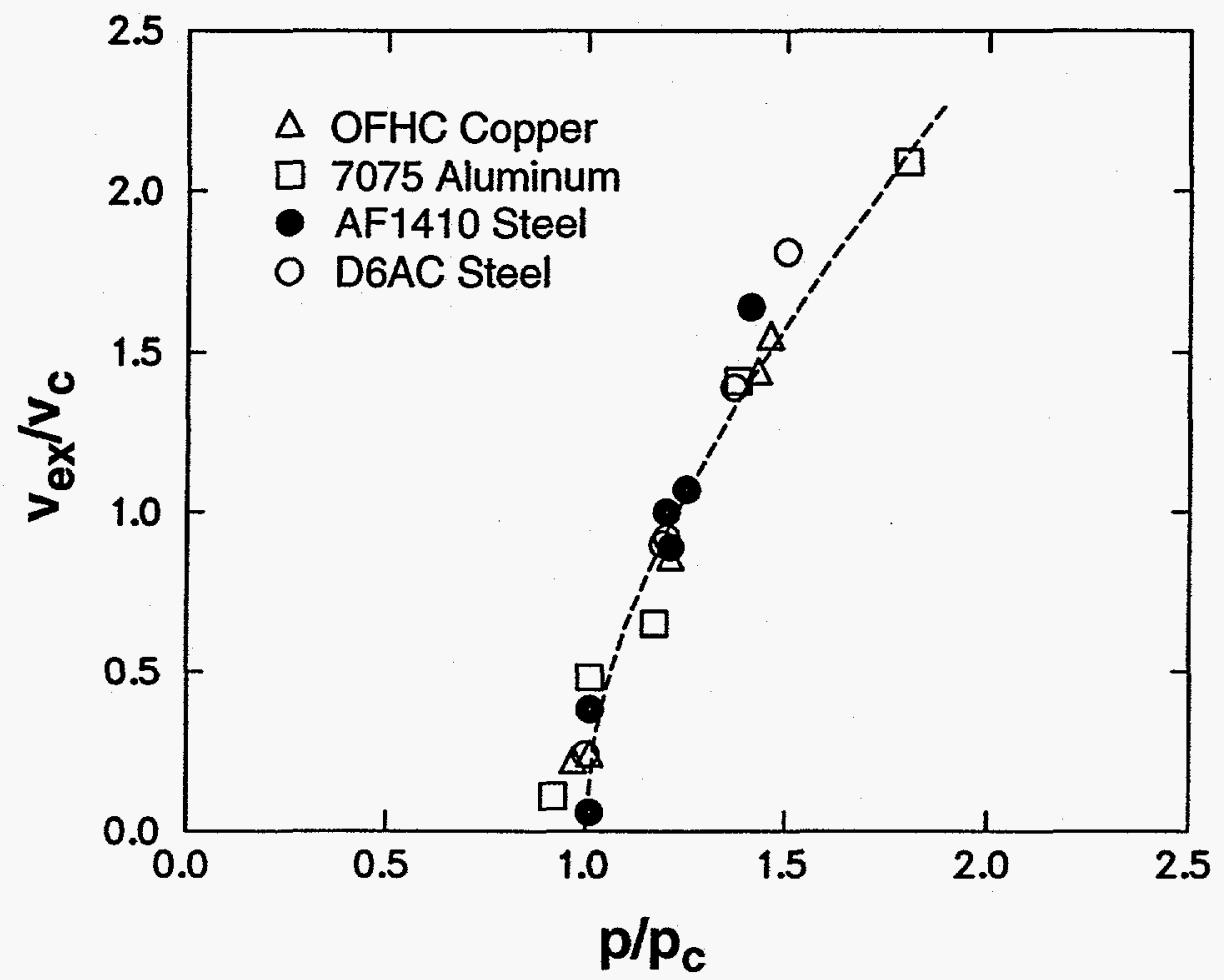

Figure 8. Expansion velocity data normalized by parameters resulting from an energy balance assessment of the data (Equation 13). 


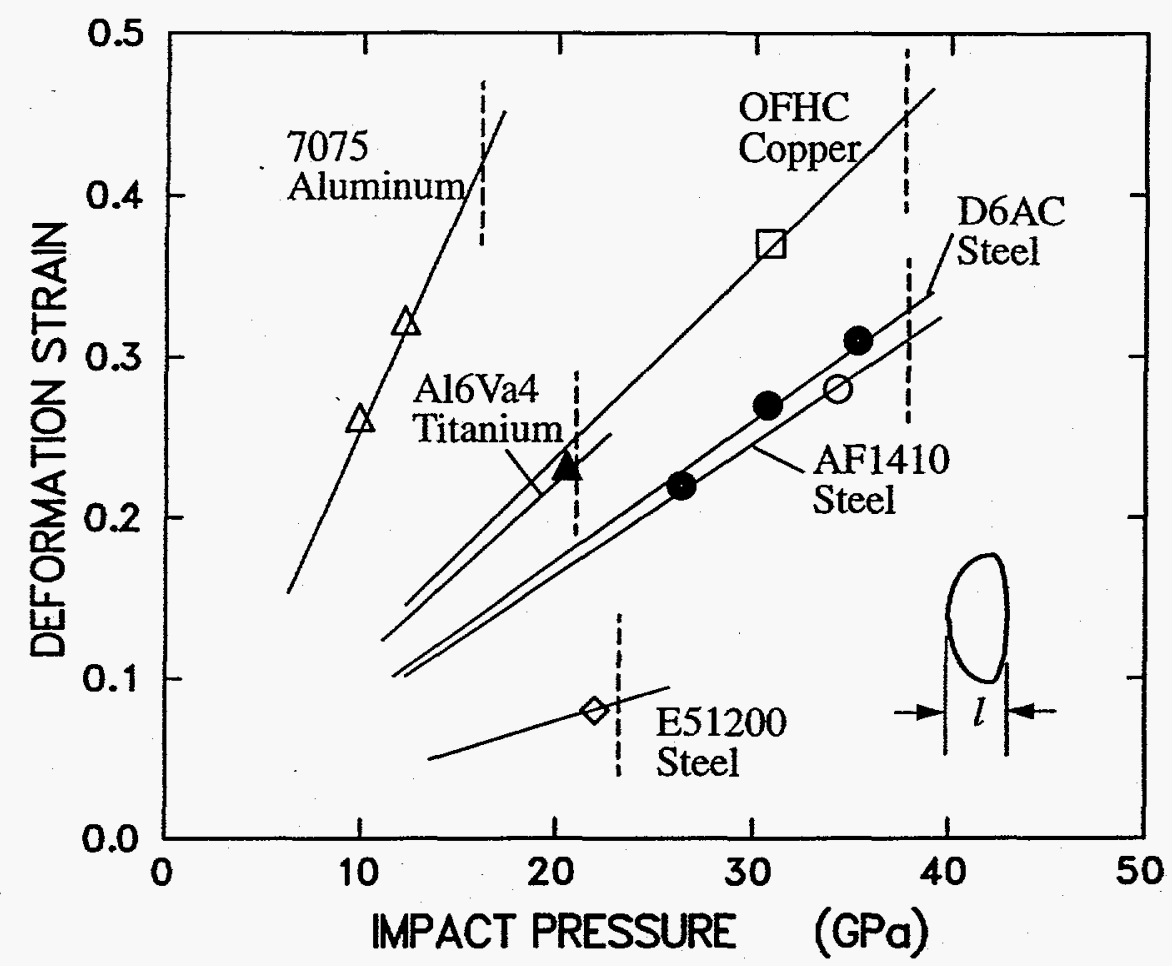

Figure 9. Strain-to-failure data for selected metals based on the sphere-on-plate impact tests.

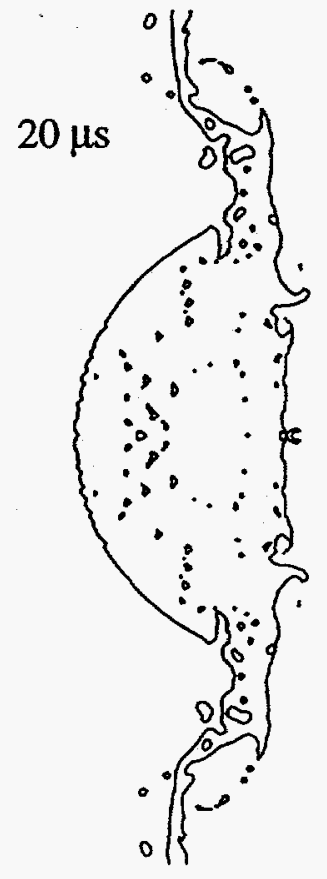

(a)

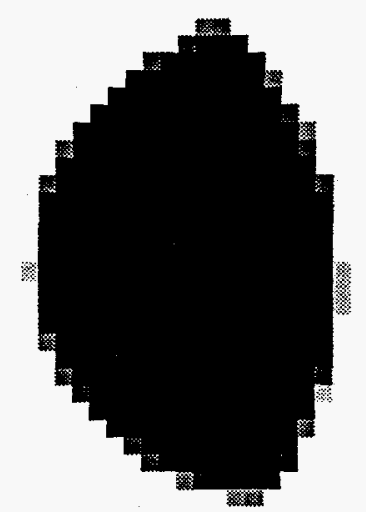

(b)

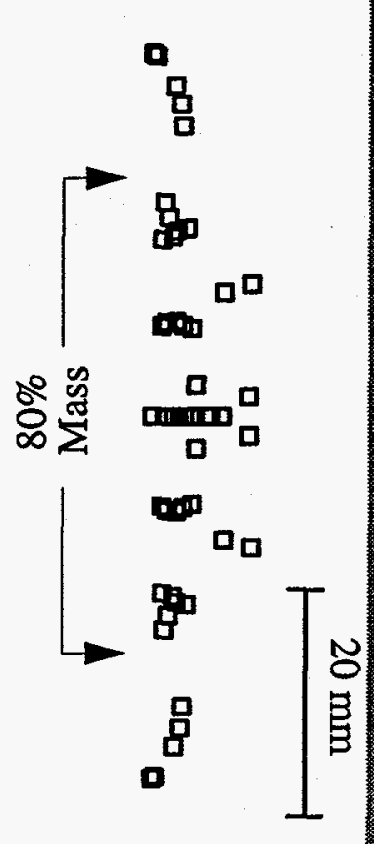

(c)

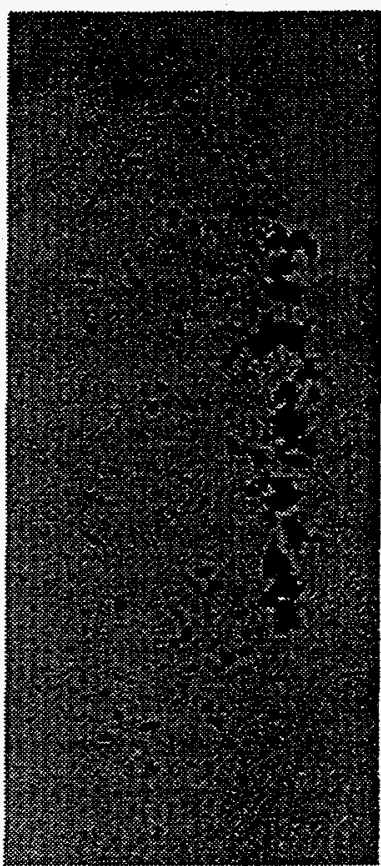

(d)

Figure 10. Comparison of numerical (a) and experimental (b) deformed aluminum spheres for $2230 \mathrm{~m} / \mathrm{s}$ impact onto $2.92 \mathrm{~mm}$ PMMA. Comparison of extrapolated fragments (c) and experimental (d) debris cloud for $3920 \mathrm{~m} / \mathrm{s}$ impact onto $2.92 \mathrm{~mm}$ PMMA. 